\section{A) Check for updates}

Cite this: Analyst, 2019, 144, 3843

\title{
A novel label-free terbium(III)-aptamer based aptasensor for ultrasensitive and highly specific detection of acute lymphoma leukemia cells
}

\author{
Siwen Wu, (D) † Nuo Yang, † Liping Zhong, Yiqun Luo, Huiling Wang, Wenlin Gong, \\ Sufang Zhou, Yanmei Li, Jian He, Haopei Cao, Yong Huang* and Yongxiang Zhao*
}

Acute leukemia is a malignant clonal disease of hematopoietic stem cells with a high prevalence and mortality rate. However, there are no efficient tools to facilitate early diagnosis and treatment of leukemia. Therefore, development of new methods for the early diagnosis and prevention of leukemia, especially non-invasive diagnosis at the cellular level, is imperative. Here, a label-free signal-on fluorescence aptasensor based on terbium(III)-aptamer ( $\mathrm{Tb}^{3+}$-apt) was applied for the detection of leukemia. The aptamer sensitizes the fluorescence of $\mathrm{Tb}^{3+}$ and forms the strong fluorescent $\mathrm{Tb}^{3+}$-apt probe. The target cells, the $\mathrm{T}$-cell acute lymphoblastic leukemia cell line (CCRF-CEM) combined with the $\mathrm{Tb}^{3+}$-apt probe to form the $\mathrm{Tb}^{3+}$-apt-CEM complex, were removed by centrifugation, and the supernatant containing a small amount of the $\mathrm{Tb}^{3+}$-apt probe was detected using a fluorescence spectrophotometer. The logarithm of cell concentration showed a good linear relationship $\left(R^{2}=0.9881\right)$ with the fluorescence signal. The linear range for CCRF-CEM detection was $5-5 \times 10^{6}$ cells per $\mathrm{ml}$, while the detection limit was 5 cells per $\mathrm{ml}$ of the binding buffer. Clinical samples were collected from 100 cases, and the specificity and positive rates detected by this method were up to $94 \%$ and $90 \%$, respectively. Therefore, a single-stranded DNAsensitized terbium(III) luminescence method diagnostic was developed which is rapid, sensitive, and economical and can be used for diagnosis of various types of leukemia at the early stage.

Received 3rd December 2018 Accepted 8th March 2019

DOI: $10.1039 / c 8 a n 02342 \mathrm{e}$ rsc.li/analyst the bone marrow is one of the mainstay methods used to detect leukemia in clinics, although other testing methods are used, ${ }^{3}$ including fluorescent labeling, ${ }^{4-6}$ cytochemistry, ${ }^{7,8}$ flow cytometry, ${ }^{9-11}$ immunohistochemical ${ }^{12,13}$ and immunophenotype analysis, and aptamer-conjugated polymeric nanoparticles. ${ }^{14,15}$ However, most of these methods not only are costly, time-consuming, complicated and labor-intensive, but also require a combination of sophisticated instruments, which have low sensitivity and demand multiple step processing making them unsuitable for simple and rapid medical analysis. Therefore, there is a need to explore a highly specific, sensitive and cost-effective method to facilitate early diagnosis and treatment of leukemia. This especially demands for noninvasive diagnostic and prevention techniques targeted at the cellular level based on modern analytical chemistry to improve the treatment and survival rates of the patients.

In order to get highly specific targeting probes, scientists have used systematic evolution of ligands by exponential enrichment (SELEX) to screen for the new type of molecular recognition elements - nucleic acid aptamers. ${ }^{16-18}$ Due to their characteristic high affinity to target molecules, aptamers are often referred to as "chemical antibodies". ${ }^{19}$ Compared with antibodies, aptamers are cheaper, less invasive and easily 
reproducible due to the unambiguous primary structure. ${ }^{20-22}$ Aptamers can bind not only to inorganic ions, small molecules, biological macromolecules, but also to supramolecular substances such as cells, viruses, and pathological tissue sections. ${ }^{23-25}$ Moreover, the synthesis of aptamers is easy and uses short cycles, ${ }^{26,27}$ and aptamers show good stability ${ }^{28}$ and are easy to modify. ${ }^{29,30}$ The emergence of aptamers has provided a new identification tool to the biochemistry and the biomedical communities. In recent years, nucleic aptamer-based biosensors have shown promising applications in the detection of cancer. ${ }^{31,32}$ In 2006, Tan et al. first selected the live tumor cell line, ${ }^{33}$ human acute lymphoblastic leukemia cell line CCRF-CEM, as target cells to screen for high specificity and affinity sgc8 aptamers. Subsequently, the sge8 aptamer has found wide usage in the detection of acute lymphoblastic leukemia. ${ }^{34,35}$

Rare earth terbium ion $\left(\mathrm{Tb}^{3+}\right)$ is a promising non-labeled fluorescent probe that has attracted a great deal of attention ${ }^{36}$ because of its unique optical properties, such as a long fluorescence lifetime, large Stokes shift and narrow emission band. ${ }^{37,38} \mathrm{Fu}$ et al. reported that single-stranded oligonucleotides can enhance the fluorescence of rare earth terbium ions $\left(\mathrm{Tb}^{3+}\right)$, but not the double-stranded DNA. ${ }^{39}$ Another study reported that $\mathrm{G}$ base-rich single-stranded oligonucleotides can effectively sensitize the fluorescence of $\mathrm{Tb}^{3+} \cdot{ }^{40}$ Based on these reports, Wei et al. designed a G-base-rich hairpin probe which sensitizes the $\mathrm{Tb}^{3+}$ fluorescence. The heavy metal lead $\left(\mathrm{Pb}^{2+}\right)$ competitively binds this hairpin probe to quench the fluorescence of $\mathrm{Tb}^{3+}$. This strategy allows a highly sensitive nonlabeled detection of $\mathrm{Pb}^{2+}$ (detection limit of $\left.0.1 \mathrm{nM}\right){ }^{41}$

Inspired by the above studies, this study leveraged on the characteristics of nucleic acid aptamers and single-stranded DNA sensitized rare earth $\mathrm{Tb}^{3+}$ fluorescence to design a nonlabeled signal-sensitive fluorescence method for the detection of CCRF-CEM cells. This method is based on the principle that the aptamer sensitizes the fluorescence of $\mathrm{Tb}^{3+}$ and forms a strong fluorescent $\mathrm{Tb}^{3+}$-apt probe. After the target cells CCRFCEM combined with $\mathrm{Tb}^{3+}$-apt to form a $\mathrm{Tb}^{3+}$-apt-CEM complex, the supernatant is obtained by centrifugation, and then the supernatant was detected by fluorescence spectrophotometer. The concentration of CCRF-CEM cells in 5-5 $\times$ $10^{6}$ cells per $\mathrm{ml}$ showed a good linear relationship between the logarithmic value and the fluorescence signal $\left(R^{2}=0.9881\right)$, and the detection limit was up to 5 cells per ml. This label-free signal sensitized fluorescence method has the advantages of high selectivity, easy operation and rapidity and is expected to provide a robust, simple, and inexpensive novel method for the ultrasensitive diagnosis of acute lymphoblastic leukemia.

\section{Experimental}

\subsection{Materials}

The label-Free Sgc8 aptamer (apt) with a sequence of $5^{\prime}$ ATCTAACTGCTGC GCCGCCGGGAAAATACTGTACGGTTAGA-3' and the label-Free random aptamer (apt-) with a sequence of
5'-ATGTGGCTGCTGCGCCGCCGGGA

AAATACTGT ACGGTTAGA-3' were purchased from Shanghai Sangon Biological Engineering Technology \& services (Shanghai, China). 4-(2-hydroxyethyl) piperazine-1-ethanesulfonic acid (HEPES, $\mathrm{pH}=7.2-7.4,>99.5 \%$ ) and the nitrate of metal salts $(>99 \%)$, including potassium $\left(\mathrm{K}^{+}\right)$, sodium $\left(\mathrm{Na}^{+}\right)$, silver $\left(\mathrm{Ag}^{+}\right)$, magnesium $\left(\mathrm{Mg}^{2+}\right)$, calcium $\left(\mathrm{Ca}^{2+}\right)$, copper $\left(\mathrm{Cu}^{2+}\right)$, zinc $\left(\mathrm{Zn}^{2+}\right)$, iron $\left(\mathrm{Fe}^{3+}\right)$, and terbium $\left(\mathrm{Tb}^{3+}\right)$, were purchased from SigmaAldrich, Inc. All solutions were produced with ultra-pure water of 18.2 M $\Omega$ purified from a Milli-Q purification system (Milli-Pore, Bedford, MA, USA). CCRF-CEM, Ramos (human Burkitt's lymphoma cell lines) cells, and K562 (chronic myelocytic leukemia cell lines), HL-60 (human promyelocytic leukemic cell lines), Thp-1 (mononuclear phagocyte system) and U937 (tissue cell lymphoma cells) cell lines were purchased from the Cell Bank of the Chinese Academy of Sciences (Shanghai, China).

\subsection{Instruments}

All fluorescence measurements were carried out in a $350 \mu \mathrm{L}$ quartz cuvette. The excitation wavelength was $292 \mathrm{~nm}$, and the emission spectra were recorded with both excitation and emission slits of $5 \mathrm{~nm}$ using an F-7000 fluorescence spectrophotometer (Hitachi Company, Tokyo, Japan). The peak intensities were obtained at $545 \mathrm{~nm}$, and the sampling range was recorded from $460 \mathrm{~nm}$ to $560 \mathrm{~nm}$. All the atomic force microscopy imaging was performed by fluorescence microscopy (Nikon DS-Ri1; Nikon, Tokyo, Japan). Cell Counting Kit-8 was bought from Dojindo, Japan.

\subsection{Cell culture}

CCRF-CEM, Ramos cells, and K562, HL-60, Thp-1 and U937 cell lines were cultured in $5 \%$ carbon dioxide (95\% oxygen) at $37{ }^{\circ} \mathrm{C}$ for 3 days and the medium of 1640 which contained $10 \%$ fetal bovine serum (FBS, Gibco) and $100 \mathrm{U} \mathrm{mL}^{-1}$ penicillin-streptomycin (Gibco, Grand Island, NY, USA).

\subsection{Preparation of the $\mathrm{Tb}^{3+}$-apt fluorescent aptasensor}

A suitable aptamer $(50 \mu \mathrm{M})$ diluted by $252 \mu \mathrm{l}$ PBS (phosphatebuffered saline, $10 \mathrm{mM}, \mathrm{pH} 7.2$ ) and $\mathrm{Tb}^{3+}$ solution diluted by the same volume HEPES buffer (200 mM, $1 \mathrm{mM}$ magnesium nitrate, $\mathrm{pH}$ 7.2) were put in storage solution at $4{ }^{\circ} \mathrm{C}$ in the dark. Magnesium ions were used to stabilize the oligonucleotides' conformation and decrease the non-specific binding between other metal ions and the oligonucleotides. The final concentrations of the oligonucleotides $(5 \mu \mathrm{M}$ oligonucleobases) and terbium nitrate $(20 \mathrm{mM})$ were prepared in PBS. For example, an application-type mixture ( $5 \mu \mathrm{M}$ oligonucleobases, $20 \mathrm{mM} \mathrm{Tb}^{3+}$ ) was formed by adding $160 \mu \mathrm{l}$ PBS to $40 \mu$ l storage solution.

\subsection{Optimization of the fluorescent aptasensor}

To optimize the $\mathrm{Tb}^{3+}$ concentration and detection conditions, the probe preparation method is the same as the preparation of the $\mathrm{Tb}^{3+}$-apt fluorescent aptasensor above, just fixing one condition to optimize the others. Different concentrations of 
$\mathrm{Tb}^{3+}$ (5 mM, $10 \mathrm{mM}, 15 \mathrm{mM}, 20 \mathrm{mM}, 25 \mathrm{mM}, 30 \mathrm{mM}$ ) with oligonucleotides $(5 \mu \mathrm{M})$ were detected. In order to explore the effect of $\mathrm{pH}$ value on fluorescence intensity of $\mathrm{Tb}^{3+}$, the fluorescence intensity of $\mathrm{Tb}^{3+}(20 \mathrm{mM})$ with oligonucleotides $(5 \mu \mathrm{M})$ in the application-type mixture $(\mathrm{pH} 4.8, \mathrm{pH} 6.0, \mathrm{pH} 7.2$, $\mathrm{pH}$ 8.4, pH 9.6, pH 11.0, pH 12.0, pH 13.0) was detected. And the fluorescence intensity of $\mathrm{Tb}^{3+}(20 \mathrm{mM})$ with oligonucleotides $(5 \mu \mathrm{M})$ after incubation with CCRF-CEM $\left(1 \times 10^{6}\right.$ cells per $200 \mu \mathrm{l})$ at room temperature for different time periods (5 min, $10 \mathrm{~min}, 20 \mathrm{~min}, 30 \mathrm{~min}, 40 \mathrm{~min}, 60 \mathrm{~min}$ ) was also detected. All cell samples were centrifuged at $1000 \mathrm{rpm}$ for $3 \mathrm{~min}$, then $160 \mu \mathrm{l}$ of the supernatant was collected, and the $\mathrm{pH}$ value was adjusted to 9.6 for detection by fluorescence spectroscopy at the wavelength range of $460 \mathrm{~nm}-560 \mathrm{~nm}$. Fluorescence intensity of $\mathrm{Tb}^{3+}(20 \mathrm{mM})$ with oligonucleotides $(5 \mu \mathrm{M})$ after $10 \mathrm{~min}$ of incubation with CCRF-CEM $\left(1 \times 10^{6}\right.$ cells per $\left.200 \mu \mathrm{l}\right)$ at $4{ }^{\circ} \mathrm{C}$, $25^{\circ} \mathrm{C}$ and $37{ }^{\circ} \mathrm{C}$ was detected, too. Data are expressed as the mean $\pm \mathrm{SD}$ of 3 independent experiments; the difference between fluorescence intensities obtained by the rank sum test is statistically significant $(P<0.05)$.

\subsection{Probe for the detection of cells}

A suitable aptamer $(50 \mu \mathrm{M})$ diluted by $252 \mu \mathrm{l}$ PBS $(10 \mathrm{mM}, \mathrm{pH}$ 7.2) and $\mathrm{a} \mathrm{Tb}^{3+}$ solution diluted by the same volume of HEPES buffer (200 mM, 1 mM magnesium nitrate, $\mathrm{pH}$ 7.2) were used to prepare the probe storage solution at $4^{\circ} \mathrm{C}$ in the dark. $1 \mathrm{ml}$ of CCRF-CEM cells were collected after centrifugation, the cells were washed three times with PBS, and then the supernatant was drained and re-suspended in $160 \mu \mathrm{l}$ PBS. Finally, $40 \mu \mathrm{l}$ of probe storage solution was added and mixed well. The different concentrations of CCRF-CEM cells $\left(1\right.$ to $1 \times 10^{6}$ cells per $200 \mu \mathrm{l}$ ) were incubated with the $\mathrm{Tb}^{3+}$-apt fluorescent aptasensor at $4^{\circ} \mathrm{C}$ in the dark for $10 \mathrm{~min}$. The samples were centrifuged at $1000 \mathrm{rpm}$ for $3 \mathrm{~min}$, then $160 \mu \mathrm{l}$ of the supernatant was collected, and the $\mathrm{pH}$ value was adjusted to 9.6 for detection by fluorescence spectroscopy at the wavelength range of $460 \mathrm{~nm}-560 \mathrm{~nm}$.

\subsection{Specificity assay}

The fluorescence spectrophotometer detected different bloodrelated cancer cells. To investigate the specificity of the $\mathrm{Tb}^{3+}$ apt fluorescent aptasensor, an F-7000 fluorescence spectrophotometer and a confocal fluorescence microscope were used to test different cells, including CCRF-CEM, HL-60 cells, Ramos cells, K562 cells, PBL cells (peripheral blood lymphocytes), Thp- 1 cells and U937 cells. Each of the $200 \mu$ l reaction systems including $1 \times 10^{6}$ cells was centrifuged at $1000 \mathrm{rpm}$ for 3 min to collect $160 \mu \mathrm{l}$ (removing fluid that may contain cells at the bottom of $40 \mu \mathrm{l}$ ) of the supernatant, and the $\mathrm{pH}$ value was adjusted to 9.6 for detection using the F-7000 fluorescence spectrophotometer.

Immunofluorescence imaging was performed in different blood-related cancer cells. Cells were collected in a $1.5 \mathrm{ml}$ centrifugation tube, washed three times with $\mathrm{PBS}$, incubated with the $\mathrm{Tb}^{3+}$-apt fluorescent aptasensor at $4{ }^{\circ} \mathrm{C}$ in the dark for 10 min and then washed again with PBS. The cells were fixed with $4 \%$ paraformaldehyde (Sigma-Aldrich, St Louis, MO, USA) for $10 \mathrm{~min}$, washed with PBS, and stained with 4',6-diamidino2-phenylindole dihydrochloride (DAPI; Life Technologies, Foster City, CA, USA) for $5 \mathrm{~min}$ in the dark. The cells were finally washed with PBS and examined by fluorescence microscopy.

\subsection{Detection of clinical samples}

Blood samples were collected from 20 ALL (acute lymphoblastic leukemia) patients, 60 non-ALL patients, and 20 normal subjects based on clinically diagnosed classifications. All samples were from the First Affiliated Hospital of Guangxi Medical University. These experiments were approved by the Ethics Committee of Guangxi Medical University, and patient's informed consent was obtained before the experiment. $5 \mathrm{ml}$ of peripheral blood of each case was obtained with anticoagulants, and human peripheral blood lymphocyte separation solution (Solarbio, Cat. No. P8610) was added for gradient centrifugation at a rotation speed of $1000 \mathrm{~g}$ for $30 \mathrm{~min}$. The white film layer between plasma and separation solution was taken. $200 \mu \mathrm{l}$ of the reaction systems (detection of the cell reaction system above) was added, incubated for $10 \mathrm{~min}$, and then centrifuged at $1000 \mathrm{rpm}$ for $3 \mathrm{~min}$. $160 \mu \mathrm{l}$ of the supernatant was obtained, the $\mathrm{pH}$ value was adjusted to 9.6, and the supernatant fluorescence was detected using the F-7000 fluorescence spectrophotometer.

\subsection{Statistical analyses}

Each experiment was carried out in triplicate. Data are expressed as the mean \pm SD or as the median (range). All statistical analyses were performed using GraphPad Prism 6.02 (GraphPad Software, San Diego, CA, USA). $P<0.05$ was considered statistically significant.

\section{Results and discussion}

\subsection{Principle of the $\mathrm{Tb}^{3+}$-apt fluorescent aptasensor}

Based on the characteristics of nucleic acid aptamers and single-stranded DNA sensitized rare earth $\mathrm{Tb}^{3+}$ fluorescence, a label-free signal sensitized fluorescence method was developed in this study for the detection of CCRF-CEM cells in acute lymphoblastic leukemia. The detection principle is shown in Scheme 1. The hairpin type single-chain aptamer (the yellow hairpin structure sequence in the figure) can sensitize $\mathrm{Tb}^{3+}$

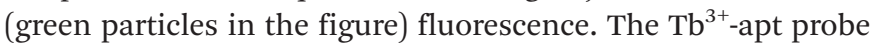
can recognize the CCRF-CEM cells specifically to form the $\mathrm{Tb}^{3+}$-apt-CEM complex, and the supernatant of the $\mathrm{Tb}^{3+}$-aptCEM complex collected by centrifugation may be used for fluorescence detection. Compared with the $\mathrm{Tb}^{3+}$-apt-nontarget cells complex, the fluorescence signal of the corresponding supernatant was significantly reduced. In contrast, in the absence of the CCRF-CEM cells, the $\mathrm{Tb}^{3+}$-apt probe was still present in the supernatant and there was no significant change in the fluorescence strength. 


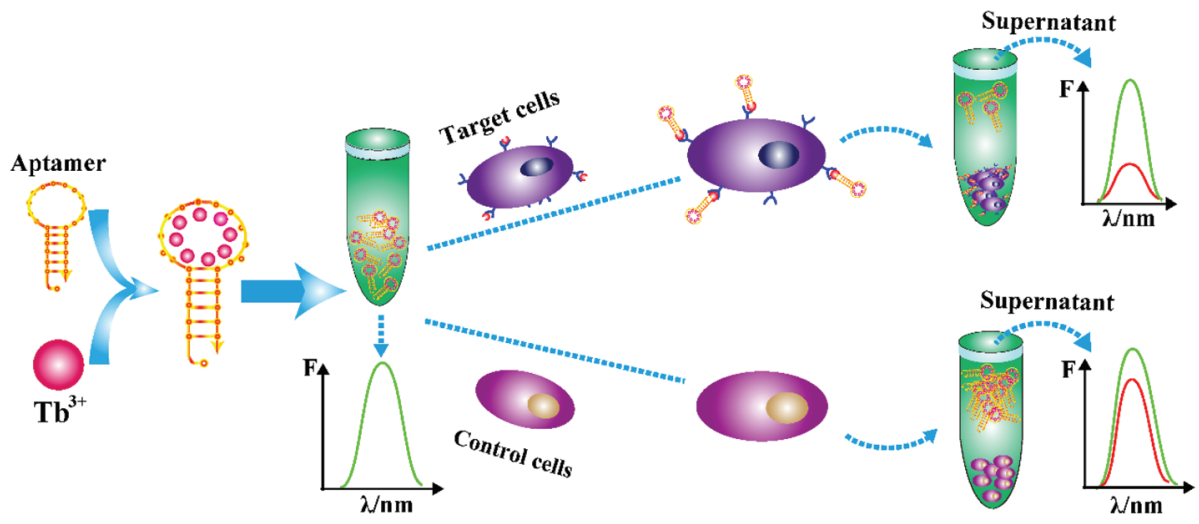

Scheme 1 Schematic illustration of the $\mathrm{Tb}^{3+}$-apt fluorescent aptasensor for detection of CCRF-CEM cells.

\subsection{Characterization of $\mathrm{Tb}^{3+}$ fluorescence}

The feasibility of this method was first verified by fluorescence spectroscopy, and the results are shown in Fig. 1A. The fluorescence intensity of $\mathrm{Tb}^{3+}$-apt was the strongest. When the non-target Romas cells were added to the $\mathrm{Tb}^{3+}$-apt probe solution, there was barely any change in the fluorescence intensity, whereas the fluorescence intensity was significantly decreased when the CEM cells were added. And when the non-target G-base rich single stranded oligonucleotides $\mathrm{Tb}^{3+}$-apt(-) were incubated with the CEM cells, the fluorescence intensity was hardly attenuated. A statistical graph showed similar results (Fig. 1B). The PTK7 protein on the surface of the CEM cell membrane specifically binds to the Sgc8 aptamer, and the target cells then removed the probe by centrifugation, leaving almost no $\mathrm{Tb}^{3+}$-apt probe in the supernatant, leading to a
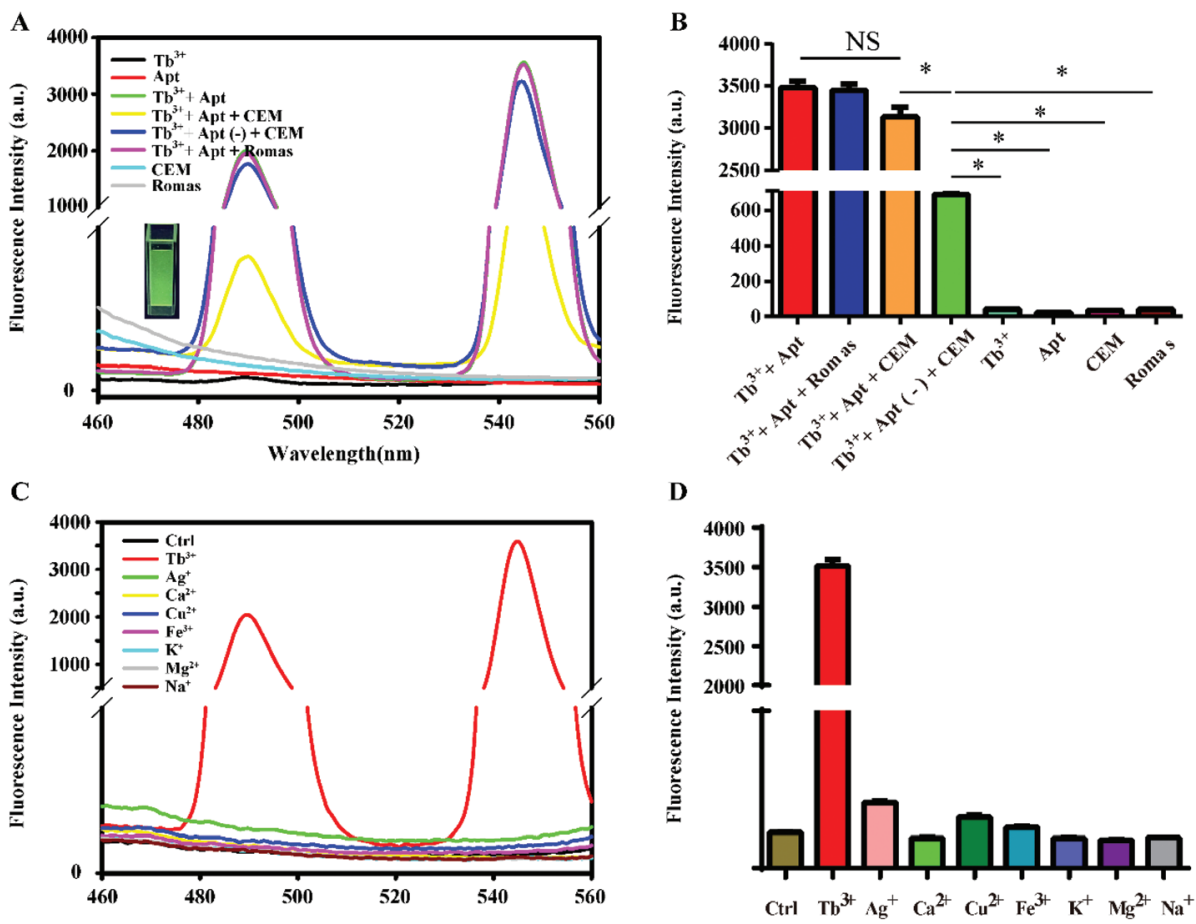

Fig. 1 (A) Fluorescence emission spectra of $\mathrm{Tb}^{3+}$, apt and CCRF-CEM cells under different conditions: $\mathrm{Tb}^{3+} ; \mathrm{Apt}^{(5} \mathrm{uM}^{3}$; $\mathrm{Tb}^{3+}+\mathrm{apt}^{3} \mathrm{~Tb}^{3+}+$ apt + CCFF-CEM; $\mathrm{Tb}^{3+}+$ apt(-) + CCFF-CEM; $\mathrm{Tb}^{3+}+$ apt + Romas; Tb ${ }^{3+}(20 \mathrm{mM}) ;$ CCRF-CEM $\left(1 \times 10^{6}\right.$ cells); Romas $\left(1 \times 10^{6}\right.$ cells). Excitation: $290 \mathrm{~nm}$. (B) Quantitative analysis of fluorescence emission spectra of $\mathrm{Tb}^{3+}$, apt, apt(-) and CCRF-CEM under different conditions. NS, not statistically significant, ${ }^{*} P<0.05$, statistically significant. (C) Fluorescence emission spectra of the aptamer with different metal ions. When the Sgc 8 aptamer combines with the terbium ion, the fluorescence is markedly enhanced, whereas the other metal ions barely show any fluorescence when mixed with the Sgc8 aptamer. (D) Statistical analysis of fluorescence emission spectra of the aptamer with different metal ions, showing significant differences between $\mathrm{Tb}^{3+}$ and other ions that mixed with the aptamer. 
rapid decrease of the fluorescence. While the individual $\mathrm{Tb}^{3+}$, apt, CEM, and Romas cells are almost non-fluorescent, the $\mathrm{Tb}^{3+}$-apt probe emits green fluorescence under ultraviolet light. In order to confirm the characteristics of $\mathrm{Tb}^{3+}$ sensitized specificity of DNA, $\mathrm{Tb}^{3+}$ and other different ions in the physical environment were reacted with aptamers. The results showed that when the aptamer binds to the terbium ion, the fluorescence is markedly enhanced, whereas the other metal ions (including $\mathrm{K}^{+}, \mathrm{Na}^{+}, \mathrm{Ag}^{+}, \mathrm{Cu}^{2+}, \mathrm{Zn}^{2+}, \mathrm{Mg}^{2+}, \mathrm{Ca}^{2+}, \mathrm{Fe}^{3+}$ ) show almost no fluorescence when they are bound to the aptamer (Fig. 1C), and a statistical graph of the reaction of $\mathrm{Tb}^{3+}$ and other different ions with aptamers showed a similar trend (Fig. 1D). This result also indicates that the hairpin type single-chain aptamer can sensitize $\mathrm{Tb}^{3+}$ fluorescence. However, silver, calcium, copper, iron, potassium, magnesium, and sodium ions do not have this function. The specific principle is similar to the hairpin structure of aptamers that may be affected by the coordination of strontium ions and aptamer polyguanine rings studied. ${ }^{41}$

\subsection{Experimental condition optimization}

The experimental conditions were optimized, and the results are shown in Fig. 2. The aptamer concentration was fixed at $5 \mu \mathrm{M}$, and the $\mathrm{Tb}^{3+}$ concentration was then optimized. When the concentration of $\mathrm{Tb}^{3+}$ was $20 \mathrm{mM}$, the fluorescence inten-

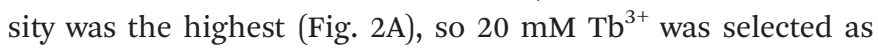

the optimal concentration. By adjusting the $\mathrm{pH}$ of the probe $\left(\mathrm{Tb}^{3+}\right.$-apt) solution, it was found that the fluorescence was strongest when the $\mathrm{pH}$ was 9.6; thus, $\mathrm{pH}=9.6$ was chosen (Fig. 2B). When the incubation time was in the range of 5 to $10 \mathrm{~min}$, the fluorescence intensity increased with time, while the incubation time in the range of 10 to $30 \mathrm{~min}$ led to a plateau in the fluorescence intensity. Considering the time efficiency, 10 min was selected as the optimum incubation time for follow-up experiments (Fig. 2C). At the same time, the fluorescence was most intense when incubated at $4{ }^{\circ} \mathrm{C}$ (Fig. 2D); therefore, $4^{\circ} \mathrm{C}$ was chosen as the optimal hybridization temperature.

\subsection{Analytical performance of the aptasensor}

Under the selected optimal conditions, the sensitivity of the fluorescence method was examined. As shown in Fig. 3A, the difference in the fluorescence intensity gradually decreases with the increase of the concentration of the CEM cells (a. $\mathrm{Tb}^{3+}$-apt; b. $10^{0}$ cells per $200 \mu \mathrm{l}$, c. $10^{1}$ cells per $200 \mu \mathrm{l}$, d. $10^{2}$ cells per $200 \mu \mathrm{l}$, e. $10^{3}$ cells per $200 \mu \mathrm{l}$, f. $10^{4}$ cells per $200 \mu \mathrm{l}$, g. $10^{5}$ cells per $200 \mu \mathrm{l}$, h. $10^{6}$ cells per $200 \mu \mathrm{l}$ ). In the range of 1 to $10^{6}$ cells per $200 \mu \mathrm{l}$, the logarithm of the concentration of the CEM cells showed a good linear relationship with the fluorescence signal, the fluorescence intensity as a function of $\mathrm{Tb}^{3+}$-apt minus logarithm of concentration of the cells. The results were the average of four repetitive experiments, with
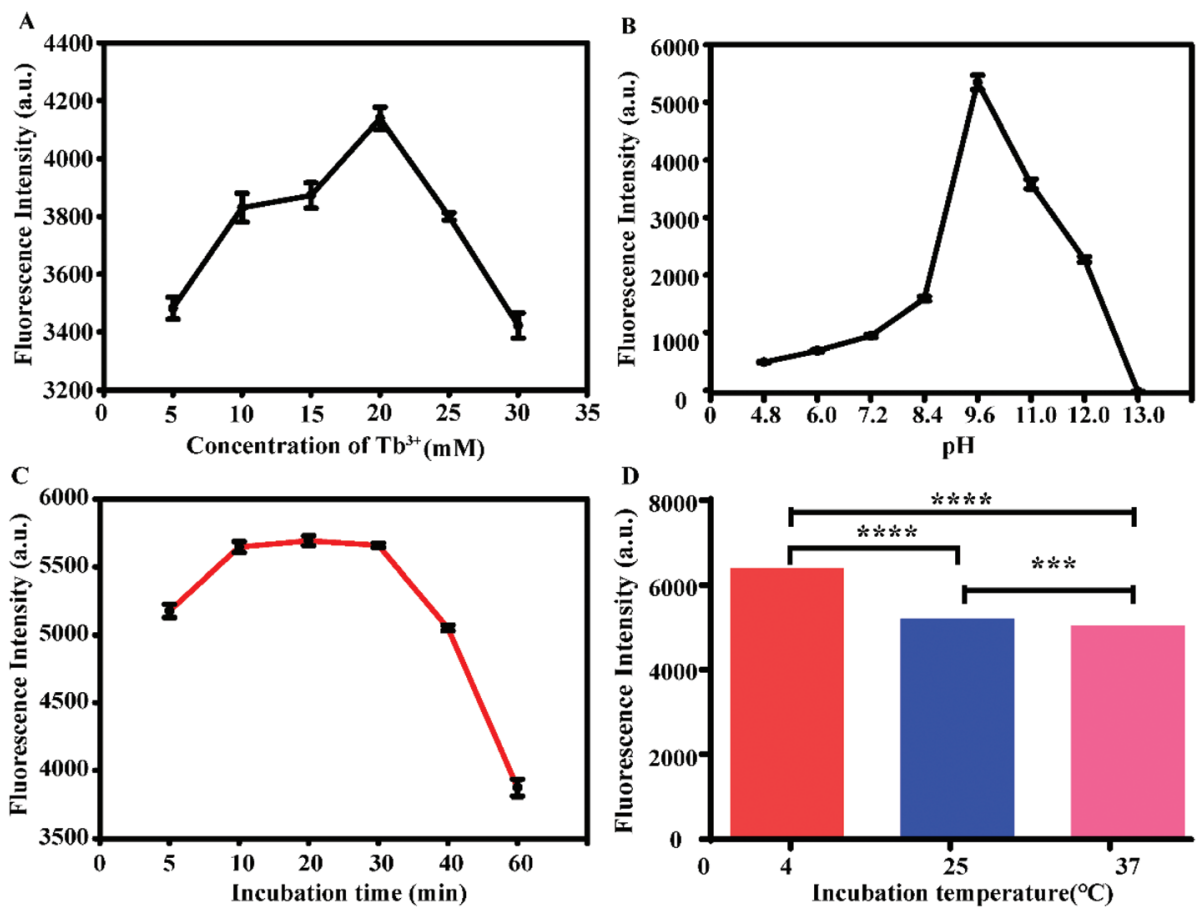

Fig. 2 Optimization of $\mathrm{Tb}^{3+}$ concentration and detection conditions. (A) Concentration of $\mathrm{Tb}^{3+}(5 \mathrm{mM}, 10 \mathrm{mM}, 15 \mathrm{mM}, 20 \mathrm{mM}, 25 \mathrm{mM}, 30 \mathrm{mM})$ with oligonucleotides $(5 \mu \mathrm{M})$. (B) Fluorescence intensity of $\mathrm{Tb}^{3+}(20 \mathrm{mM})$ with oligonucleotides $(5 \mu \mathrm{M})$ in the application-type mixture $(\mathrm{pH} 4.8, \mathrm{pH} 6.0, \mathrm{pH}$ 7.2, $\mathrm{pH}$ 8.4, $\mathrm{pH}$ 9.6, $\mathrm{pH}$ 11.0, $\mathrm{pH}$ 12.0, $\mathrm{pH} 13.0)$. (C) Fluorescence intensity of $\mathrm{Tb}^{3+}(20 \mathrm{mM})$ with oligonucleotides $(5 \mu \mathrm{M})$ after incubation with CCRF-CEM $\left(1 \times 10^{6}\right.$ cells per $\left.200 \mu \mathrm{l}\right)$ at room temperature for different incubation periods. (D) Fluorescence intensity of Tb ${ }^{3+}$ with oligonucleotides in the application-type mixture $\left(5 \mu \mathrm{M}\right.$ oligonucleobases, $\left.20 \mathrm{mM} \mathrm{Tb}^{3+}, \mathrm{pH} 7.2\right)$ after 10 min of incubation with CCRF-CEM (1 $\times 10^{6}$ cells per $\left.200 \mu \mathrm{l}\right)$ at $4{ }^{\circ} \mathrm{C}, 25^{\circ} \mathrm{C}$ and $37^{\circ} \mathrm{C}$. Data are expressed as the mean \pm SD of 3 independent experiments; ${ }^{* \star *} P<0.001$. 
A

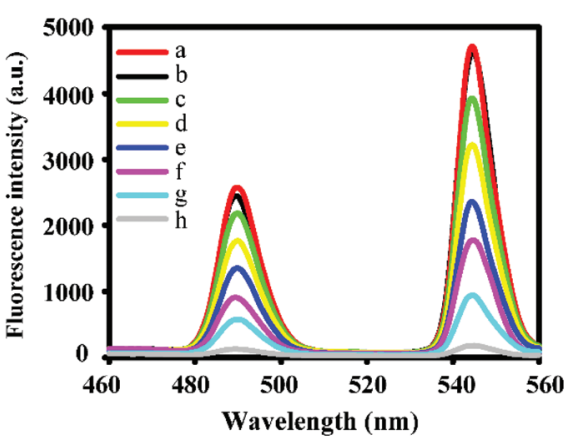

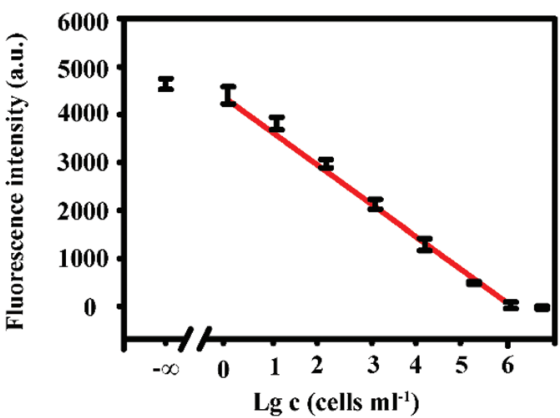

C

D
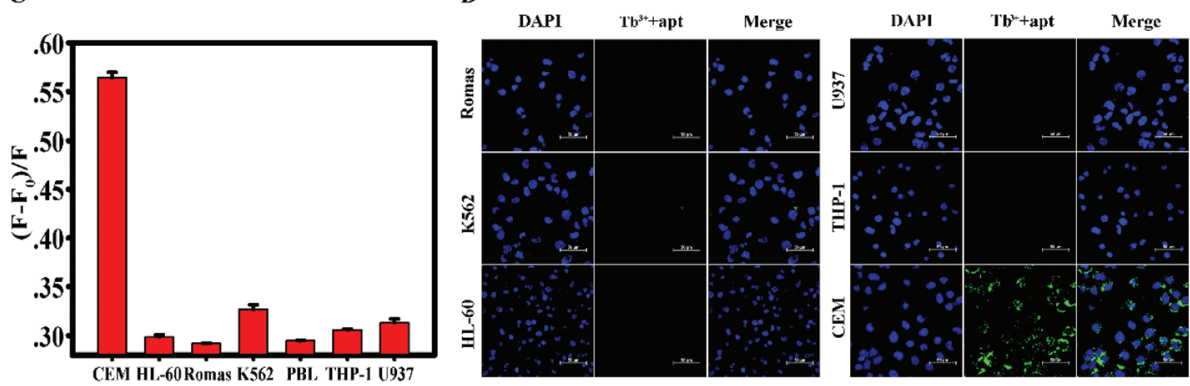

Fig. 3 (A) Fluorescence emission spectra of the $\mathrm{Tb}^{3+}$-apt fluorescent aptasensor in the presence of different concentrations of CCRF-CEM cells (a. $\mathrm{Tb}^{3+}$-apt, b. $10^{\circ}$ cells per $200 \mu \mathrm{l}$, c. $10^{1}$ cells per $200 \mu \mathrm{l}$, d. $10^{2}$ cells per $200 \mu \mathrm{l}$, e. $10^{3}$ cells per $200 \mu \mathrm{l}$, f. $10^{4}$ cells per $200 \mu \mathrm{l}$, g. $10^{5}$ cells per $200 \mu \mathrm{l}$, h. $10^{6}$ cells per $200 \mu \mathrm{l}$ ). (B) Linear relationship between the fluorescence intensity and the concentration of CCRF-CEM cells. (C) Specificity of the fluorescent aptasensor for CEM. The fluorescence intensity rate $\left(F-F_{0}\right) / F$ of the $\mathrm{Tb}^{3+}$-apt fluorescent aptasensor in the presence of $C E M, H L-60$, Ramos, K562, PBL, THP-1, and U937 cells, respectively $\left(1 \times 10^{6}\right.$ cells per $\left.200 \mu \mathrm{l}\right)$, where $F$ and $F_{0}$ are the fluorescence intensity without and with detection cells at $545 \mathrm{~nm}$. Excitation: $290 \mathrm{~nm}$. (D) Fluorescence micrographs of six different cells after mixing with Tb ${ }^{3+}$-apt. Nuclei were stained with DAPI. Scale bars indicate $50 \mu \mathrm{m}$.

Table 1 Comparison of analytical properties of CCRF-CEM cytosensors

\begin{tabular}{|c|c|c|c|}
\hline Detection method & Linear range & $\begin{array}{l}\text { Detection } \\
\text { limit/mL }\end{array}$ & Ref. \\
\hline Colorimetric & $3.30 \times 10^{3}-2.69 \times 10^{3}$ & 214 & 42 \\
\hline Quartz crystal microbalance & $8.00 \times 10^{3}-1.00 \times 10^{5}$ & 8000 & 43 \\
\hline Flow cytometry & $7.50 \times 10^{3}-6.25 \times 10^{5}$ & 750 & 45 \\
\hline Fluorescence & $5.00-5.00 \times 10^{6}$ & 5 & This work \\
\hline
\end{tabular}

error bars indicating the standard deviation (Fig. 3B). The linear equation was $F=-680.2 C+5750.6(F$ is the fluorescence intensity, $C$ is $\mathrm{Tb}^{3+}$-apt minus logarithm of concentration of the cells), $R^{2}=0.9881$, and the detection limit is 5 cells per $\mathrm{ml}$. Compared with other reported fluorescence methods in Table 1, this method can significantly reduce the detection limit, suggesting a better sensitivity.

Under the selected optimal conditions, the specificity of the fluorescence method was investigated. According to the results shown in Fig. 3C, the intensity of fluorescence of the CEM cells was significantly higher than that of other control cells. In addition, as shown in Fig. 3D, the probes bound well to the target cell CEM as detected using the confocal microscope, emitting green fluorescence, whereas the probes did not bind to other cells, as only blue nuclei could be seen. These experi-

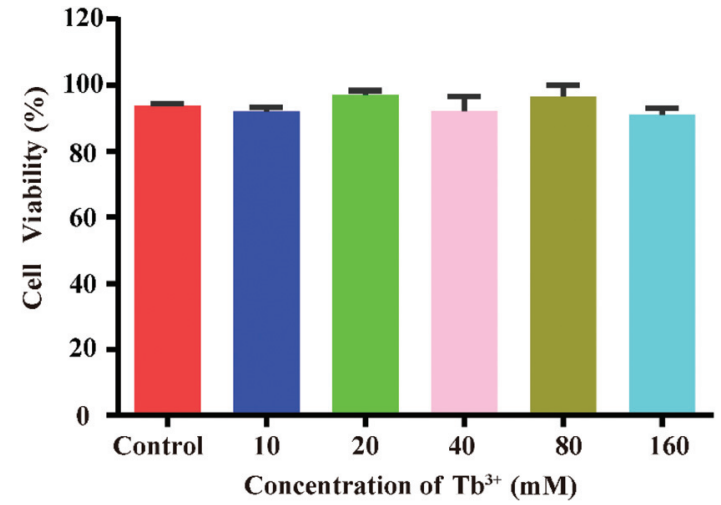

Fig. 4 Relative viability of CCRF-CEM cells incubated with $\mathrm{Tb}^{3+}$-apt at different concentrations for $24 \mathrm{~h}$. 
Table 2 General clinical information

\begin{tabular}{|c|c|c|c|c|}
\hline Number & Gender & Age (years) & Sample & Diagnosis \\
\hline & & & Acute lymphoblastic leukemia patients (ALL) & \\
\hline 1 & Female & 28 & Peripheral blood/bone marrow & T-ALL-L1 \\
\hline 2 & Female & 13 & Peripheral blood & T-ALL-L2 \\
\hline 3 & Male & 6 & Peripheral blood/bone marrow & T-ALL-L1 \\
\hline 4 & Male & 8 & Peripheral blood/bone marrow & T-ALL-L1 \\
\hline 5 & Female & 9 & Peripheral blood/bone marrow & T-ALL-L2 \\
\hline 6 & Male & 20 & Peripheral blood/bone marrow & T-ALL-L2 \\
\hline 7 & Male & 12 & Peripheral blood/bone marrow & T-ALL-L1 \\
\hline 8 & Male & 19 & Peripheral blood/bone marrow & T-ALL-L1 \\
\hline 9 & Male & 29 & Peripheral blood/bone marrow & T-ALL-L2 \\
\hline 10 & Female & 5 & Peripheral blood/bone marrow & T-ALL-L1 \\
\hline 11 & Female & 34 & Peripheral blood/bone marrow & T-ALL-L1 \\
\hline 12 & Male & 8 & Peripheral blood/bone marrow & T-ALL-L2 \\
\hline 13 & Male & 9 & Peripheral blood/bone marrow & T-ALL-L1 \\
\hline 14 & Female & 15 & Peripheral blood/bone marrow & B-ALL \\
\hline 15 & Female & 12 & Peripheral blood/bone marrow & T-ALL-L1 \\
\hline 16 & Male & 54 & Peripheral blood/bone marrow & T-ALL-L2 \\
\hline 17 & Male & 2 & Peripheral blood/bone marrow & T-ALL-L2 \\
\hline 18 & Male & 9 & Peripheral blood/bone marrow & T-ALL-L1 \\
\hline 19 & Male & 6 & Peripheral blood/bone marrow & T-ALL-L1 \\
\hline \multirow[t]{2}{*}{20} & Female & 6 & Peripheral blood/bone marrow & T-ALL-L2 \\
\hline & & & Acute myelocytic leukemia patients (AML) & \\
\hline 1 & Male & 59 & Peripheral blood/bone marrow & AML-M1 \\
\hline 2 & Male & 33 & Peripheral blood/bone marrow & AML-M3 \\
\hline 3 & Female & 65 & Peripheral blood/bone marrow & AML-M0 \\
\hline 4 & Male & 45 & Peripheral blood/bone marrow & AML-M1 \\
\hline 5 & Female & 58 & Peripheral blood/bone marrow & AML-M1 \\
\hline 6 & Male & 13 & Peripheral blood/bone marrow & AML-M1 \\
\hline 7 & Male & 10 & Peripheral blood/bone marrow & AML-M1 \\
\hline 8 & Female & 5 & Peripheral blood/bone marrow & AML-M1 \\
\hline 9 & Female & 5 & Peripheral blood/bone marrow & AML-M3 \\
\hline 10 & Male & 8 & Peripheral blood/bone marrow & AML-M4 \\
\hline 11 & Male & 54 & Bone marrow & AML-M3 \\
\hline 12 & Male & 7 & Peripheral blood/bone marrow & AML-M3 \\
\hline 13 & Female & 31 & Bone marrow & AML-M3 \\
\hline 14 & Male & 21 & Peripheral blood/bone marrow & AML-M3 \\
\hline 15 & Female & 54 & Peripheral blood/bone marrow & AML-M1 \\
\hline 16 & Male & 23 & Peripheral blood/bone marrow & AML-M1 \\
\hline 17 & Female & 5 & Peripheral blood/bone marrow & AML-M1 \\
\hline 18 & Female & 18 & Bone marrow & AML-M3 \\
\hline 19 & Male & 17 & Peripheral blood/bone marrow & AML-M1 \\
\hline \multirow{2}{*}{$\begin{array}{l}19 \\
20\end{array}$} & Male & 17 & Peripheral blood/bone marrow & AML-M4 \\
\hline & & & Chronic lymphocytic leukemia (CLL) & \\
\hline 1 & Male & 58 & Peripheral blood/bone marrow & B-CLL \\
\hline 2 & Male & 45 & Peripheral blood/bone marrow & B-CLL \\
\hline 3 & Male & 57 & Peripheral blood/bone marrow & B-CLL \\
\hline 4 & Female & 6 & Peripheral blood/bone marrow & B-CLL \\
\hline 5 & Female & 8 & Bone marrow & B-CLL \\
\hline 6 & Female & 9 & Peripheral blood/bone marrow & B-CLL \\
\hline 7 & Female & 12 & Bone marrow & B-CLL \\
\hline 8 & Female & 7 & Peripheral blood & B-CLL \\
\hline 9 & Male & 5 & Peripheral blood/bone marrow & B-CLL \\
\hline 10 & Male & 16 & Peripheral blood/bone marrow & B-CLL \\
\hline 11 & Male & 23 & Peripheral blood/bone marrow & T-CLL \\
\hline 12 & Male & 18 & Bone marrow & B-CLL \\
\hline 13 & Male & 17 & Peripheral blood/bone marrow & B-CLL \\
\hline 14 & Female & 25 & Peripheral blood/bone marrow & B-CLL \\
\hline 15 & Female & 29 & Peripheral blood/bone marrow & B-CLL \\
\hline 16 & Female & 5 & Peripheral blood/bone marrow & T-CLL \\
\hline 17 & Male & 6 & Peripheral blood & B-CLL \\
\hline 18 & Male & 6 & Peripheral blood & B-CLL \\
\hline 19 & Female & 8 & Bone marrow & B-CLL \\
\hline 20 & Female & 59 & Peripheral blood/bone marrow & B-CLL \\
\hline
\end{tabular}

Male $\quad 56$

Male 34

Female $\quad 26$

Male 21

Male 5

Female 14

\section{Other}

Peripheral blood/bone marrow Peripheral blood/bone marrow Peripheral blood/bone marrow Peripheral blood/bone marrow Peripheral blood/bone marrow Peripheral blood/bone marrow

Myelodysplastic histiocytosis Myelodysplastic histiocytosis Myelodysplastic histiocytosis Myelodysplastic histiocytosis Thrombocytopenic purpura Thrombocytopenic purpura 
Table 2 (Contd.)

\begin{tabular}{|c|c|c|c|c|}
\hline Number & Gender & Age (years) & Sample & Diagnosis \\
\hline 7 & Male & 12 & Peripheral blood/bone marrow & Non-Hodgkin's lymphoma \\
\hline 8 & Male & 52 & Peripheral blood/bone marrow & Non-Hodgkin's lymphoma \\
\hline 9 & Female & 51 & Peripheral blood/bone marrow & Thrombocytopenic purpura \\
\hline 10 & Female & 25 & Peripheral blood/bone marrow & Iron deficiency anemia \\
\hline 11 & Female & 18 & Peripheral blood/bone marrow & Iron deficiency anemia \\
\hline 12 & Male & 15 & Peripheral blood/bone marrow & Iron deficiency anemia \\
\hline 13 & Female & 14 & Peripheral blood/bone marrow & The Mediterranean anemia \\
\hline 14 & Male & 16 & Peripheral blood/bone marrow & The Mediterranean anemia \\
\hline 15 & Male & 29 & Peripheral blood/bone marrow & The Mediterranean anemia \\
\hline 16 & Female & 38 & Peripheral blood/bone marrow & The Mediterranean anemia \\
\hline 17 & Male & 45 & Peripheral blood/bone marrow & The Mediterranean anemia \\
\hline 18 & Female & 56 & Peripheral blood/bone marrow & Hodgkin’s lymphoma \\
\hline 19 & Male & 29 & Peripheral blood/bone marrow & Hodgkin's lymphoma \\
\hline 20 & Male & 37 & $\begin{array}{l}\text { Peripheral blood/bone marrow } \\
\text { Healthy volunteers Normal }\end{array}$ & Hodgkin's lymphoma \\
\hline 1 & Female & 18 & Peripheral blood & Normal \\
\hline 2 & Male & 20 & Peripheral blood & Normal \\
\hline 3 & Male & 25 & Peripheral blood & Normal \\
\hline 4 & Female & 24 & Peripheral blood & Normal \\
\hline 5 & Male & 24 & Peripheral blood & Normal \\
\hline 6 & Male & 48 & Peripheral blood & Normal \\
\hline 7 & Female & 45 & Peripheral blood & Normal \\
\hline 8 & Male & 34 & Peripheral blood & Normal \\
\hline 9 & Male & 35 & Peripheral blood & Normal \\
\hline 10 & Male & 28 & Peripheral blood & Normal \\
\hline 11 & Male & 28 & Peripheral blood & Normal \\
\hline 12 & Male & 27 & Peripheral blood & Normal \\
\hline 13 & Female & 26 & Peripheral blood & Normal \\
\hline 14 & Male & 26 & Peripheral blood & Normal \\
\hline 15 & Male & 26 & Peripheral blood & Normal \\
\hline 16 & Male & 27 & Peripheral blood & Normal \\
\hline 17 & Male & 25 & Peripheral blood & Normal \\
\hline 18 & Male & 25 & Peripheral blood & Normal \\
\hline 19 & Female & 24 & Peripheral blood & Normal \\
\hline 20 & Male & 24 & Peripheral blood & Normal \\
\hline
\end{tabular}

Table 3 Comparison of clinical diagnosis rate and detection rate of this experimental method

\begin{tabular}{lll}
\hline & $\begin{array}{l}\text { Number of } \\
\text { clinical } \\
\text { diagnoses }\end{array}$ & $\begin{array}{l}\text { Number of } \\
\text { diagnoses } \\
\text { by this } \\
\text { experimental } \\
\text { method }\end{array}$ \\
Group & 20 & $\begin{array}{l}18 \\
\text { ALL group }\end{array}$ \\
Non-ALL group and the normal group & 80 & 5
\end{tabular}

ALL, acute lymphoblastic leukemia.

mental results show that this method has strong anti-interference and high specificity for CEM cells.

\subsection{The cytotoxicity of the probe}

In order to investigate whether the apt- $\mathrm{Tb}^{3+}$ probe is destructive to the sample during the assay, in vitro toxicity assessment was performed at the cellular level using the Cell Counting Kit8. The CEM cells were co-cultured with different concentrations of probes, and the cell viability was measured after coculture for a certain period. Fig. 4 shows that as the probe concentration increases $(10 \mathrm{mM}, 20 \mathrm{mM}, 40 \mathrm{mM}, 80 \mathrm{mM}$, $160 \mathrm{mM})$, the viability of the cells is reduced, but even at a maximum concentration of $160 \mathrm{mM}$, the probe is incubated with the CEM cells for $4 \mathrm{~h}$; therefore, the vitality can be preserved above $90 \%$. This result indicates that the probe has

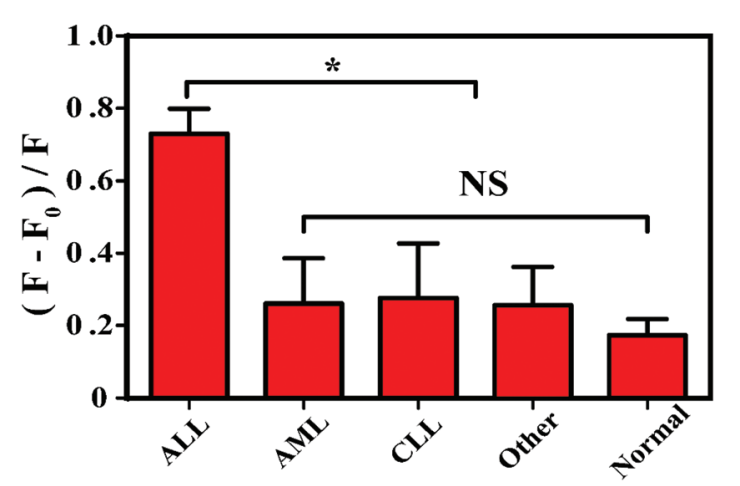

Fig. 5 Specificity of the fluorescent aptasensor for clinical samples. The fluorescence intensity rate $\left(F-F_{0}\right) / F$ of the $\mathrm{Tb}^{3+}$-apt fluorescent aptasensor in the presence of ALL (acute lymphoblastic leukemia), AML (acute myelocytic leukemia), CLL (chronic lymphocytic leukemia), other (including myelodysplastic histiocytosis, Hodgkin's lymphoma, nonHodgkin's lymphoma, thrombocytopenic purpura, iron deficiency anemia, the Mediterranean anemia), normal, where $F$ and $F_{0}$ are the fluorescence intensity without and with detection cells at $545 \mathrm{~nm}$. Excitation: $290 \mathrm{~nm}$. 
good biocompatibility with no toxicity to cells during a short period.

\subsection{Analysis of clinical samples}

In order to evaluate the applicability of this method, 100 clinical samples were collected, of which 20 were from clinically diagnosed ALL patients, 60 were from non-acute lymphoblastic leukemia patients, and 20 were from normal healthy volunteers. Table 3 shows a specificity of $94 \%$ and a positive rate of $90 \%$, while clinical sample specific information is shown in Table 2. Obviously, the ALL group is significantly different from the non-ALL group and the normal group as shown in Fig. 5. These results indicate that the fluorescence method can be applied for the detection of acute leukemia in blood samples of clinical patients.

\section{Conclusion}

In this work, we successfully developed a non-labeled signal sensitized fluorescence method for the detection of leukemia based on the characteristics of nucleic acid aptamer sensitized rare earth $\mathrm{Tb}^{3+}$ fluorescence. Compared with known cancer cell assay methods, this strategy has some superior features. First, the strategy of detection is inexpensive and convenient because no labels are required. Second, the affinity, stability, and specificity of the aptamer bound by $\mathrm{Tb}^{3+}$ are greatly enhanced under optimal conditions. Lastly, it is applicable for many types of cancer cells that use different aptamers to identify probes. Therefore, this simple, rapid, sensitive, universal and specific cancer cell detection strategy provides a new approach for the detection of cancer cells by the label-free fluorescence method. Compared with the antigen-antibody sandwich technique, this method shortens the detection time, enabling rapid analysis and formulation of treatment plans for patients as it provides a detailed classification of leukemia in real-time samples.

\section{Conflicts of interest}

There are no conflicts of interest to declare.

\section{Acknowledgements}

This work was supported by the Programs for National Natural Scientific Foundation of China (No. 81430055); Changjiang Scholars and Innovative Research Team in University (No. IRT_15R13); Guangxi Science and Technology Base and Talent Special Project (No. AD17129003).

All experiments were performed in accordance with the Guidelines of Declaration of Helsinki Principles and approved by the Ethics Committee at Guangxi Medical University. Informed consents were obtained from human participants of this study.

\section{References}

1 H. M. Meng, H. Liu, H. Kuai, R. Peng, L. Mo and X. B. Zhang, Chem. Soc. Rev., 2016, 45, 2583-2602.

2 J. Munoz, N. Shah, K. Rezvani, C. Hosing, C. M. Bollard, B. Oran, A. Olson, U. Popat, J. Molldrem, I. K. McNiece and E. J. Shpall, Stem Cells Transl. Med., 2014, 3, 1435-1443.

3 R. L. Siegel, S. A. Fedewa, K. D. Miller, A. Goding-Sauer, P. S. Pinheiro, D. Martinez-Tyson and A. Jemal, CA-Cancer J. Clin., 2015, 65, 457-480.

4 S. C. Chan, W. L. Yau, W. Wang, D. K. Smith, F. S. Sheu and H. M. Chen, J. Pept. Sci., 1998, 4, 413-425.

5 S. Boddington, T. D. Henning, E. J. Sutton and H. E. Daldrup-Link, J. Visualized Exp., 2008, 13, 685.

6 S. Choi, J. Yu, S. A. Patel, Y. L. Tzeng and R. M. Dickson, Photochem. Photobiol. Sci., 2011, 10, 109-115.

7 H. Shi, Z. Tang, Y. Kim, H. Nie, Y. F. Huang, X. He, K. Deng, K. Wang and W. Tan, Chem. - Asian J., 2010, 5, 2209-2213.

8 K. Pulford, N. Lecointe, K. Leroy-Viard, M. Jones, D. Mathieu-Mahul and D. Y. Mason, Blood, 1995, 85, 675684.

9 M. Doan, I. Vorobjev, P. Rees, A. Filby, O. Wolkenhauer, A. E. Goldfeld, J. Lieberman, N. Barteneva, A. E. Carpenter and H. Hennig, Trends Biotechnol., 2018, 36, 649-652.

10 G. Rymkiewicz, B. Grygalewicz, M. Chechlinska, K. Blachnio, Z. Bystydzienski, J. Romejko-Jarosinska, R. Woroniecka, M. Zajdel, K. Domanska-Czyz and D. Martin-Garcia, Mod. Pathol., 2018, 31, 732-743.

11 L. M. Neckers, W. K. Funkhouser, J. B. Trepel, J. Cossman and H. G. Gratzner, Exp. Cell Res., 1985, 156, 429-438.

12 I. B. Rozenvald, M. D. Richardson, L. Brock and R. L. Maiese, Arch. Pathol. Lab. Med., 2017, 141, 837-840.

13 E. A. Morgan, H. Yu, J. L. Pinkus and G. S. Pinkus, Am. J. Clin. Pathol., 2013, 139, 220-230.

14 L. C. Ho, W. C. Wu, C. Y. Chang, H. H. Hsieh, C. H. Lee and H. T. Chang, Anal. Chem., 2015, 87, 4925-4932.

15 L. Yan, H. Shi, X. He, K. Wang, J. Tang, M. Chen, X. Ye, F. Xu and Y. Lei, Anal. Chem., 2014, 86, 9271-9277.

16 D. Shangguan, L. Meng, Z. C. Cao, Z. Xiao, X. Fang, Y. Li, D. Cardona, R. P. Witek, C. Liu and W. Tan, Anal. Chem., 2008, 80, 721-728.

17 M. Ye, J. Hu, M. Peng, J. Liu, J. Liu, H. Liu, X. Zhao and W. Tan, Int. J. Mol. Sci., 2012, 13, 3341-3353.

18 A. Ganji, A. Varasteh and M. Sankian, J. Drug Targeting, 2016, 24, 1-12.

19 Q. Shen, C. Peng, Y. Zhan, L. Fan, M. Wang, Q. Zhou, J. Liu, X. Lv, Q. Tang, J. Li, X. Huang and J. Xia, Int. J. Nanomed., 2016, 11, 2133-2146.

20 B. Mondal, S. Ramlal, P. S. Lavu, B. N and J. Kingston, Front. Microbiol., 2018, 9, 179.

21 M. Mascini, I. Palchetti and S. Tombelli, Angew. Chem., Int. Ed., 2012, 51, 1316-1332.

22 S. Philippou, N. P. Mastroyiannopoulos, N. Makrides, C. W. Lederer, M. Kleanthous and L. A. Phylactou, Mol. Ther.-Nucleic Acids, 2018, 10, 199-214. 
23 X. Li, Y. Peng, Y. Chai, R. Yuan and Y. Xiang, Chem. Commun., 2016, 52, 3673-3676.

24 Y. Tan, X. Wei, Y. Zhang, P. Wang, B. Qiu, L. Guo, Z. Lin and H. H. Yang, Anal. Chem., 2015, 87, 11826-11831.

25 J. Ni, W. Yang, Q. Wang, F. Luo, L. Guo, B. Qiu, Z. Lin and H. Yang, Biosens. Bioelectron., 2018, 105, 182-187.

26 Y. Wang, Z. Li, H. Li, M. Vuki, D. Xu and H. Y. Chen, Biosens. Bioelectron., 2012, 32, 76-81.

27 H. Li, M. Wang, C. Wang, W. Li, W. Qiang and D. Xu, Anal. Chem., 2013, 85, 4492-4499.

28 S. Feng, C. Chen, W. Wang and L. Que, Biosens. Bioelectron., 2018, 105, 36-41.

29 C. Chen, Z. Yang and X. Tang, Med. Res., 2018, 38, 829-869.

30 Y. Yao, X. Wang, W. Duan and F. Li, Analyst, 2018, 143, 709.

31 P. Mallikaratchy, Z. Tang, S. Kwame, L. Meng, D. Shangguan and W. Tan, Mol. Cell. Proteomics, 2007, 6, 2230-2238.

32 Y. X. Zou, S. Huang, Y. Liao, X. Zhu, Y. Chen, L. Chen, F. Liu, X. Hu, H. Tu and L. Zhang, Chem. Sci., 2018, 9, 2842-2849.

33 D. Shangguan, Y. Li, Z. Tang, Z. C. Cao, H. W. Chen, P. Mallikaratchy, K. Sefah, C. J. Yang and W. Tan, Proc. Natl. Acad. Sci. U. S. A., 2006, 103, 11838-11843.
34 S. M. Taghdisi, K. Abnous, F. Mosaffa and J. Behravan, J. Drug Targeting, 2010, 18, 277-281.

35 N. M. Danesh, P. Lavaee, M. Ramezani, K. Abnous and S. M. Taghdisi, Int. J. Pharm., 2015, 489, 311-317.

36 A. Fang, H. Chen, H. Li, M. Liu, Y. Zhang and S. Yao, Biosens. Bioelectron., 2017, 87, 545-551.

37 J. Yuan and G. Wang, J. Fluoresc., 2005, 15, 559-568.

38 Z. Ye, J. Chen, G. Wang and J. Yuan, Anal. Chem., 2011, 83, 4163-4169.

39 K. L. Fu and C. Turro, J. Am. Chem. Soc., 2009, 121, 1-7.

40 M. K. Johansson, R. M. Cook, J. Xu and K. N. Raymond, J. Am. Chem. Soc., 2004, 126, 16451-16455.

41 W. Yueteng, L. Ru, W. Yaling, Z. Yuliang, C. Zhifang and G. Xueyun, Analyst, 2013, 138, 2302-2307.

42 H. Shi, D. Li, F. Xu, X. He, K. Wang, X. Ye, J. Tang and C. He, Analyst, 2014, 139, 4181-4184.

43 Y. Pan, M. Guo, Z. Nie, Y. Huang, C. Pan, K. Zeng, Y. Zhang and S. Yao, Biosens. Bioelectron., 2010, 25, 16091614.

44 J. Zhu, T. Nguyen, R. Pei, M. Stojanovic and Q. Lin, Lab Chip, 2012, 12, 3504-3513.

45 J. Yin, X. He, K. Wang, F. Xu, J. Shangguan, D. He and H. Shi, Anal. Chem., 2013, 85, 12011-12019. 